\title{
Non-invasive investigation of liver disease in haemophilic patients
}

\author{
ELIZABETH J MILLER,* CHRISTINE A LEE,* P KARAYIANNIS $†$ \\ S J HAMILTON-DUTOIT $\ddagger$ R DICK, I H C THOMAS, $\uparrow$ P B A KERNOFF* \\ From the Academic Departments of ${ }^{*}$ Haematology, $\dagger$ Medicine and $\ddagger$ Histopathology and the $\lceil$ Department of \\ Radiology, Royal Free Hospital School of Medicine and Royal Free Hospital, London
}

SUMMARY Liver biopsy specimens previously taken from 16 haemophilic patients with chronic nonA, non-B hepatitis were reviewed. The degree of fibrosis correlated with serum procollagen III peptide (sPIIIP) concentrations, measured both at the time of biopsy and $4 \cdot 25$ years later. Two patients with extremely high sPIIIP concentrations had collateral veins on computed tomography, suggesting portal hypertension. Twenty eight of 47 patients $(60 \%)$ had splenomegaly on computed tomography, and of 28 patients in whom intravenous contrast medium was used, seven (25\%) had collateral oesophageal veins.

Serum procollagen III peptide estimations and computed tomography, both non-invasive investigations, indicated that hepatic fibrosis and portal hypertension had developed in a proportion of haemophilic patients with non-A, non-B hepatitis. Infection with the human immunodeficiency virus (HIV) may modify the course of this presumably cytopathic virus infection of the liver.

Liver function tests are often abnormal in patients with haemophilia who have received coagulation factor concentrates. ${ }^{1-4}$ Liver biopsy in patients with haemophilia carries an increased risk, and consequently there have been few reports of serial liver biopsy specimens taken from this group of patients. ${ }^{67}$

The aim of this study was to use two non-invasive methods to assess the progression of liver disease in haemophilic patients. Computed tomograms, both with and without intravenous contrast, were used to measure portal vein diameter, the size of the liver and the spleen, and to detect the presence of collateral veins. Serum procollagen III peptide (sPIIIP) concentrations which have been shown to reflect the inflammatory activity and degree of established fibrosis in patients with chronic liver disease, ${ }^{8}$ were correlated with the histological findings from a series of liver biopsy specimens taken from 16 patients between July 1978 and April 1983, and with abdominal computed tomograms.

\section{Patients and methods}

Liver biopsies had been performed on 16 patients with chronic non-A, non-B hepatitis between 1978 and 1983. ${ }^{9}$ The median age at the time of biopsy was 32.5

Accepted for publication 5 May 1988 years (range 9-61 years). Fourteen patients had severe haemophilia $A$, one had moderate haemophilia $B$, and one was a female carrier of haemophilia A. In 1984 (an average of 4.25 years later, range one-six), these patients had the progression of their liver disease evaluated by abdominal computed tomogram enhanced by contrast medium to measure the size of the liver and the spleen, and the diameter of the portal vein, and to detect the presence or absence of collateral veins. Three patients had repeat computed tomograms carried out in 1986.

An additional 32 patients, 28 with severe haemophilia $A$, one with mild haemophilia $A$, two with haemophilia B (one mild and one severe), and one with severe von Willebrand's disease, had abdominal computed tomograms carried out between 1983 and 1986 . The median age was 28 years at the time of the computed tomogram (range 13-65). All had evidence of persistently or intermittently raised aspartate transaminase (AST) activity ( $>40 \mathrm{iu} / \mathrm{l})$ for at least 12 months.

Computed tomograms were carried out in 12 patients who did not have liver disease but who had the scans for other reasons. The median age was $\mathbf{5 7}$ years (range 37-71).

For the unenhanced abdominal computed tomogram, slices $8 \mathrm{~mm}$ thick were taken from the diaphragm to the lower border of the liver and spleen. There was a $15 \mathrm{~mm}$ table feed. For the enhanced 
Table Procollagen III peptide (PCP) in 16 patients with haemophilia

\begin{tabular}{|c|c|c|c|c|c|c|c|c|}
\hline Patient & $\begin{array}{l}\text { Age at } \\
\text { biopsy }\end{array}$ & Diagnosis & $\begin{array}{l}\text { Liver } \\
\text { histology }\end{array}$ & $\begin{array}{l}\text { Degree of } \\
\text { fibrosis } \\
\text { scale 0-3 }\end{array}$ & $\begin{array}{l}\text { sPIIIP at } \\
\text { liver biopsy } \\
n g / m l\end{array}$ & $\begin{array}{l}\text { sPIIIP } \\
\text { at } C T \\
n g / m l\end{array}$ & $\begin{array}{l}\text { Varices } \\
\text { on } C T\end{array}$ & $\begin{array}{l}\text { Portal vein } \\
\text { diameter } \\
\text { (repeated 1986) }\end{array}$ \\
\hline $\begin{array}{r}1 \\
2 \\
3 \\
4 \\
5 \\
6 \\
* 7 \\
8 \\
9 \\
10 \\
11 \\
12 \\
13 \\
14 \\
15 \\
16\end{array}$ & $\begin{array}{l}22 \\
23 \\
18 \\
19 \\
29 \\
54 \\
41 \\
18 \\
27 \\
32 \\
16 \\
53 \\
61 \\
57 \\
51 \\
49\end{array}$ & $\begin{array}{l}\text { VIII }<1 \% \\
\text { VIII }<1 \% \\
\text { VIII }<1 \% \\
\text { VIII }<1 \% \\
\text { VIII }<1 \% \\
\text { VIII }<16 \% \\
\text { VIII }<1 \% \\
\text { VIII }<1 \% \\
\text { IX } \quad 3 \% \\
\text { VIII }<1 \% \\
\text { VIII }<1 \% \\
\text { VIII }<1 \% \\
\text { VIII }<1 \% \\
\text { VIII }<1 \% \\
\text { VIII }<1 \% \\
\text { VIII }<1 \%\end{array}$ & $\begin{array}{ll}\text { CLH } & 0 \\
\text { CPH } & 1 \\
\text { CPH } \\
\text { CPH } \\
\text { CAH mild } \\
\text { CAH mild } \\
\text { CAH mild } \\
\text { CAH mild } \\
\text { CAH mild } \\
\text { CAH mild } \\
\text { CAH mild } \\
\text { CAH mild } \\
\text { CAH mild } \\
\text { CAH moderate } \\
\text { CAH moderate } \\
\text { CAH moderate }\end{array}$ & $\begin{array}{l}0 \\
1 \\
1 \\
1 \\
1 \\
1 \\
1 \\
1 \\
1 \\
1 \\
1 \\
1 \\
2 \\
3 \\
2 \\
3 \\
3\end{array}$ & $\begin{array}{l}11.9 \\
13 \cdot 1 \\
36 \cdot 8 \\
34.0 \\
36.3 \\
26.5 \\
13 \cdot 1 \\
21 \cdot 9 \\
\text { ND } \\
19.5 \\
36 \cdot 3 \\
21.9 \\
21.9 \\
32.0 \\
20.6 \\
23.4\end{array}$ & $\begin{array}{c}11 \cdot 6 \\
33 \cdot 1 \\
23 \cdot 2 \\
17 \cdot 8 \\
20 \cdot 7 \\
20 \cdot 7 \\
30 \cdot 5 \\
27 \cdot 6 \\
11 \cdot 6 \\
15 \cdot 4 \\
77 \cdot 3 \\
44 \cdot 6 \\
120 \\
10 \cdot 9 \\
22 \cdot 3 \\
107\end{array}$ & $\begin{array}{l}\text { No } \\
\text { No } \\
\text { Yes } \\
\text { No } \\
\text { No } \\
\text { No } \\
\text { Yes } \\
\text { No } \\
\text { No } \\
\text { Yes } \\
\text { No } \\
\text { No } \\
\text { Yes } \\
\text { No } \\
\text { No } \\
\text { Yes }\end{array}$ & $\begin{array}{l}1.2 \\
\overline{1.4} \\
1.7 \\
1.4 \\
1.1 \\
2.0 \\
2.5(1 \cdot 2) \\
1.2 \\
1.0 \\
1.0 \\
(1.6) \\
1.5(1 \cdot 1) \\
1.2 \\
1.5 \\
1.4\end{array}$ \\
\hline
\end{tabular}

*Died of AIDS

CLH = Chronic lobular hepatitis

CPH = Chronic persistent hepatitis

CAH $=$ Chronic active hepatitis

abdominal computed tomogram, $100 \mathrm{ml} 10$ hexol (Omnipaque 350) was injected intravenously, $50 \mathrm{ml}$ as a bolus and $50 \mathrm{ml}$ as an infusion during the scan sequence. The first scan was taken at the level of the portal vein to ensure maximum concentration, and continued to the lower border of the liver and spleen. The upper liver and oesophagus were then scanned using $8 \mathrm{~mm}$ thick slices; a $15 \mathrm{~mm}$ table feed was again used. The portal vein was measured at its maximum diameter.

A radioimmunoassay (RIA-gnost procollagen-IIIpeptide, Hoechst, Marburg, Germany) was used to measure sPIIIP in the 16 patients who had had their livers biopsied. Measurements were made within six months of the biopsy and at the time of the computed tomogram. All serum samples were stored at $-40^{\circ} \mathrm{C}$ until assayed.

Liver biopsies had been performed to assess chronically raised aspartate transaminase activities. The specimens were reviewed without knowledge of the other data by the histopathologist. The degree of fibrosis was graded $(0=$ none, $1=$ portal expansion, $2=$ septa, $3=$ linkage of structures, $4=$ cirrhosis).

HIV antibody was assayed using a commercially available competitive enzyme immunoassay (Wellcozyme, Wellcome Diagnostics, Dartford, England).

Statistical analysis of the data was by the nonparametric Mann-Whitney U test, using the Minitab statistical package.

\section{Results}

The results of examination of the biopsy specimens have previously been reported. ${ }^{9}$ After review the final histological diagnoses of the 16 were: chronic lobular hepatitis $(n=1)$; chronic persistent hepatitis $(n=3)$; mild chronic active hepatitis $(n=9)$; and moderate chronic active hepatitis $(n=3)$ (table).

One biopsy specimen in case 1 showed no fibrosis and the SPIIIP concentration was within normal limits (normal range 7-12 $\mathrm{ng} / \mathrm{ml}$ ). Seven of nine liver biopsy specimens that showed grade 1 fibrosis, both liver

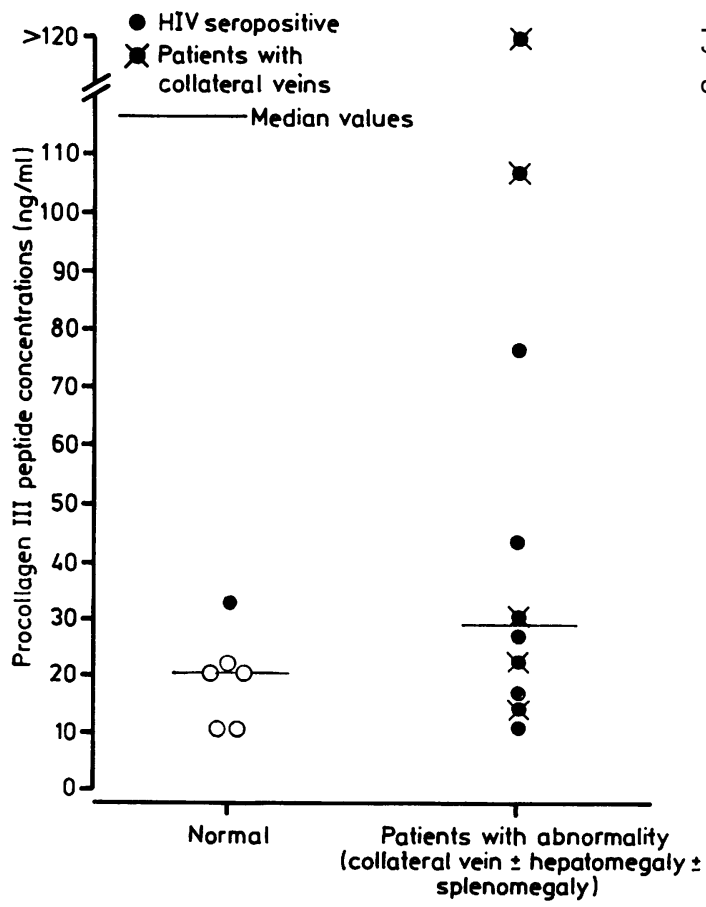

Fig 1 Findings on computed tomography and procollagen III peptide concentrations in 16 haemophilic patients who had had liver biopsy specimens taken. 


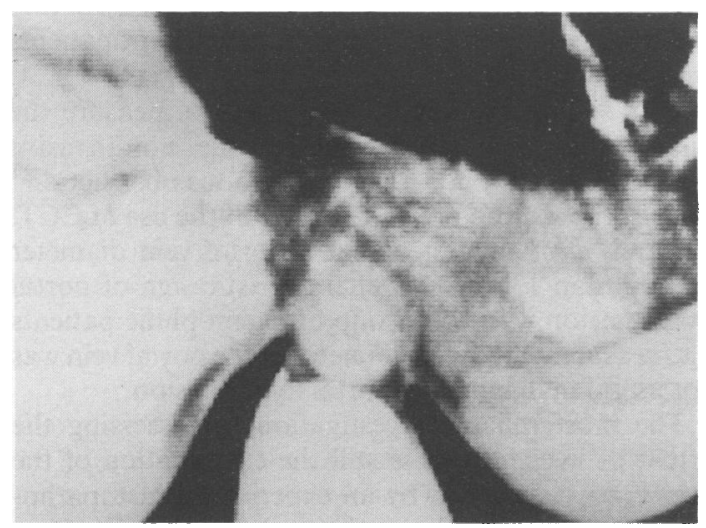

Fig 2 Anterior to the aorta; many small collateral veins surround the oesophagus.

biopsy specimens that showed grade 2 fibrosis, and all three that showed grade 3 fibrosis had abnormal sPIIIP concentrations. There was no correlation, however, between the concentration of sPIIIP and the degree of fibrosis.

The sPIIIP concentrations had increased by the time of the computed tomogram in four of nine patients whose biopsy specimens showed grade 1 fibrosis, in one of two patients whose biopsy specimens showed grade 2 fibrosis, and in two of three patients whose biopsy specimens showed grade 3 fibrosis. Pronounced increases in SPIIIP concentrations $(>40 \mathrm{ng} / \mathrm{ml})$ were associated with grade 2 or 3 fibrosis in three of four patients.

Patients who had collateral veins, hepatomegaly, or splenomegaly had higher (but not significantly$p=0.13)$ concentrations of SPIIIP than those patients who had no abnormality (fig 1). Two patients (cases 13 and 16) had concentrations of sPIIIP of greater than $100 \mathrm{ng} / \mathrm{ml}$ and both had varices on computed tomogram (in case 16 varices were seen at the time that the sPIIIP was measured, and in case 13 were seen two years later). The liver biopsy specimen from case 13 in June 1980 showed mild chronic active hepatitis and this had also progressed to cirrhosis in the liver specimens taken at necropsy in June 1987 after death from liver failure. The liver biopsy carried out in April 1980 on case 16 showed moderate chronic active hepatitis, and this had progressed to cirrhosis in the post mortem liver at necropsy in April 1986 after death from AIDS.

Seven of the 16 patients had antibodies to HIV at the time of liver biopsy. At the time of the computed tomogram, 11 of the 16 patients had been seropositive for HIV for a median of 3.6 years (range 1.2-4.4) (fig 1). Two patients (cases 7 and 16) died of AIDS in 1986.

Twenty eight of 47 patients $(60 \%)$ had splenomegaly and 14 of $47(30 \%)$ had hepatomegaly.

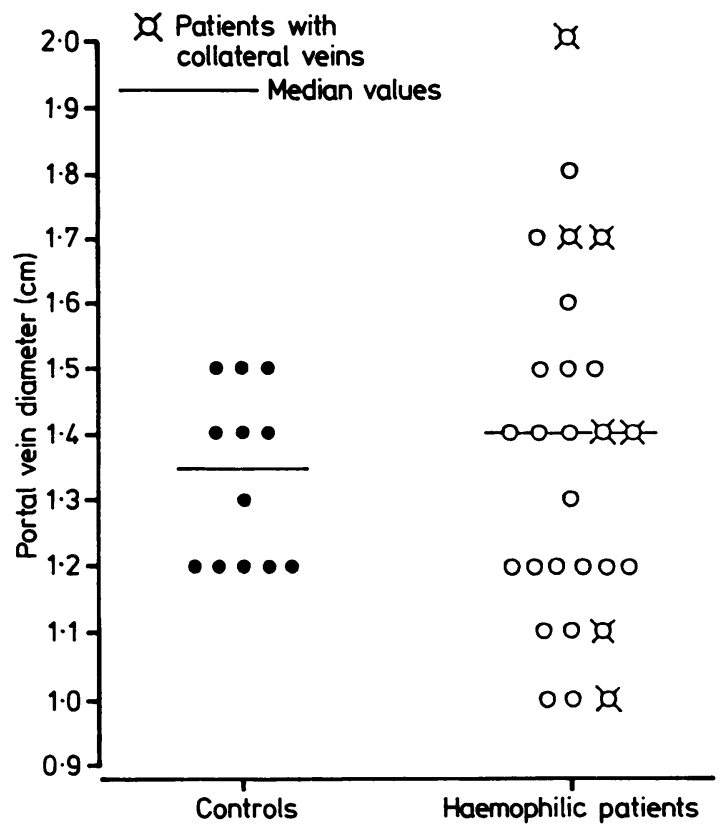

Fig 3 Diameter of the portal vein in 28 patients who were given intravenous contrast medium at computed tomography.

Oesophageal collateral veins (varices) were seen in seven of 28 patients $(25 \%)$ in whom intravenous contrast medium was used. The abdominal computed tomogram of case 13 (fig 2) after injection of contrast medium showed varices. Measurements of the diameter of the portal vein in 28 patients and 12 controls are shown in fig 3 . The median diameter of the portal vein in the control subjects was $1.35 \mathrm{~cm}$ (range 1.2-1.5). The overall median value of the patients' portal veins was $1.40 \mathrm{~cm}$ (range 1.0-2.0). The median diameter of the patients' portal veins was not significantly greater than that of control patients $(p=1 \cdot 00)$.

\section{Discussion}

The high incidence of abnormal results of liver function tests in patients with haemophilia has been well documented ${ }^{1-4}$ and a number of liver biopsies have been carried out to determine histological abnormalities. ${ }^{34910}$ Hepatic cirrhosis (an irreversible lesion leading to portal hypertension and oesophageal varices) results from the synthesis and deposition of excessive collagen, and this is normally best assessed by examination of liver biopsy specimens. "It is of concern that all but one of the 16 haemophilic patients in our study showed fibrosis on examination of biopsy specimens. This confirms the severity of the liver disease in this group of patients that has been suggested by some investigators. ${ }^{7}$ Others, however, 
have suggested that the liver disease is normally not progressive. $^{6}$

Biopsy in this group of patients has an increased risk: there is a reported mortality of $1 \%$ compared with $0.01 \%$ in non-haemophilic patients. ${ }^{5}$ When a liver biopsy specimen cannot be obtained, serum markers of increased collagen synthesis may be used to assess the risk of progression to cirrhosis. Frei et al concluded that measurement of the sPIIIP "reliably reflects activity and degree of liver fibrosis". ${ }^{12}$ In this group of haemophilic patients, however, although the sPIIIP concentration was abnormal in all but one patient who had chronic lobular hepatitis - and, by definition, no fibrosis - there was no correlation between the concentration of sPIIIP and degree of fibrosis. Thus although the concentration of sPIIIP reflects inflammatory changes in the liver it cannot be considered as an absolute index of hepatic fibrosis. ${ }^{13}$ Weigand et al have shown that a persistent rise in the sPIIIP concentration suggests continuing fibrosis and developing cirrhosis. ${ }^{14}$ In this study the two patients who showed considerable increases in SPIIIP concentrations had grade 3 fibrosis and had progressed to varices that were visible on computed tomogram. It is noteworthy that this information was obtained without the risk of repeat liver biopsy. Subsequently, evidence for progression of liver fibrosis was shown by the finding of cirrhosis at necropsy thus confirming the prediction of the sPIIIP concentrations.

The dominant causative agents for hepatitis in the haemophilic patient are thought to be non-A, non-B hepatitis viruses. ${ }^{915}$ These viruses are probably cytopathic $^{16}$ and in the presence of concurrent infection with HIV, which is immunosuppressive, there is likely to be acceleration of the underlying liver disease. It is therefore relevant that of the two patients who died from AIDS, both had varices and one had cirrhosis together with an extremely high sPIIIP concentration. Conversely, those patients who were seronegative for HIV did not have high concentrations of sPIIIP, and the sizes of the livers and spleens were normal. Thus the HIV retrovirus is yet another virus that may have a modulating influence on the hepatitis occurring in haemophilic patients. ${ }^{17}$

Computed tomograms were helpful in assessing these patients, and a high incidence of splenomegaly and hepatomegaly was found. A similar result was reported in haemophiliacs by Johnson et al. ${ }^{18}$ This may represent progressive liver disease with portal hypertension, but the continued injection of clotting factor concentrates containing a variety of antigens may also contribute to splenomegaly. The extra hepatic portal venous system can be shown with post contrast computed tomography (CCT). ${ }^{19}$ The high incidence of oesophageal varices shown by this technique suggests that these patients had developed portal hypertension.
This is consistent with the observation of Hay et al that progressive liver disease is now a problem in patients with haemophilia.'

Ultrasound scans have been used to measure the diameter of the portal vein for the non-invasive diagnosis of extra hepatic portal venous obstruction ${ }^{20}$ but we know of no previous report of the use of CCT. Weinreb et al suggested that a portal vein diameter greater than $13 \mathrm{~mm}$ is a characteristic sign of portal hypertension. ${ }^{21}$ In this group of haemophilic patients the measurement of the diameter of the portal vein was not useful in diagnosing portal hypertension.

The most reliable investigation for assessing the extent of liver fibrosis is still the examination of the liver biopsy specimen by an experienced histopathologist. In haemophilic patients, however, in whom progression of the liver disease may occur over many years, follow up with repeated liver biopsy carries a risk. For the patient with haemophilia even endoscopy is a comparatively invasive procedure, and therefore injection of contrast medium to establish the presence of varices is justified and helpful. In our study sPIIIP measurement together with computed tomograms have provided evidence of progression of liver disease in patients with haemophilia.

We thank the staff of the Royal Free Hospital computed tomography department, Professor Peter Scheuer for his helpful comments, Dr Paul Griffiths for the measurement of HIV antibodies, and Mrs $\stackrel{0}{5}$ Valerie Lee for typing the manuscript.

\section{References}

1 Levine PH, McVerry BA, Attock B, Dormandy KM. Health of the intensively treated haemophiliac, with special reference to abnormal liver chemistries and splenomegaly. Blood 1977;50: 1-19.

2 Mannucci PM, Capitanio A, Del Ninno E, Colombo M, Pareti F, Ruggeri ZM. Asymptomatic liver disease in haemophiliacs. J Clin Pathol 1975;28:620-4.

3 Preston FE, Triger DR, Underwood JCE, et al. Percutaneous liver biopsy and chronic liver disease in haemophiliacs. Lancet 1978;ii:592-94.

4 Spero JA, Lewis JH, Van Thiel DH, Hasiba U, Rabin BS. Asymptomatic structural liver disease in haemophilia. N Engl J Med 1978;298:1373-8.

5 Aledort LM, Levine PH, Hilgartner M, et al. A study of liver biopsies and liver disease among haemophiliacs. Blood 1985;66:367-72.

6 Mannucci PM, Colombo M, Rizzetto M. Non progressive course of non-A, non-B chronic hepatitis in multitransfused haemophiliacs. Blood 1982;60:655-8.

7 Hay CRM, Preston FE, Triger DR, Underwood JCE. Progressive liver disease in haemophilia: an understated problem? Lancet 1985;i:1495-8.

8 Rojkind $M$. The blue glass and the predictive value of serum amino-terminal propeptide of type III procollagen as a marker of liver fibrosis. Hepatology 1984;4:977-8. 
9 Bamber M, Murray A, Arborgh BAM, et al. Short incubation non-A, non-B hepatitis transmitted by factor VIII concentrates in patients with congenital coagulation disorders. Gut 1981;22:854-9.

10 White GC, Zeitler KD, Lesesne HR, et al. Chronic hepatitis in patients with haemophilia $A$ : histological studies in patients with intermittently abnormal liver function tests. Blood 1982;60:1259-62.

11 Review by an International Group. Acute and chronic hepatitis revisited. Lancet 1977;ii:914-9.

12 Frei A, Zimmerman A, Weigand $\mathrm{K}$. The $\mathrm{N}$ terminal propeptide of collagen type III in serum reflects activity and degree of fibrosis in patients with chronic liver disease. Hepatology 1984;4:830-4.

13 Surrenti C, Casini A, Milani S, Ambus S, Ceccatelli P, D'Agata A. Is determination of serum $\mathrm{N}$-terminal procollagen type III peptide (sPIIIP) a marker of hepatic fibrosis? Dig Dis Sci 1987;32:705-9.

14 Weigand K, Zaugg P, Frei A, Zimmerman A. Longterm follow up of serum N-terminal propeptide of collagen type III levels in patients with chronic liver disease. Hepatology 1984;4:835-8.

15 Craske J, Spooner RJD, Vandervelde EM. Evidence for existence of at least two types of factor-VIII-associated non B transfusion hepatitis. Lancet 1978;ii:1051-2.

16 Diennes HP, Popper H, Manns M, et al. New morphological aspects of auto immune hepatitis (AIH). Hepatology 1986;6:1226.

17 Lee CA, Kernoff PBA, Karayiannis P, Farci P, Thomas HC. Interactions between hepatotropic viruses in patients with haemophilia. Hepatology 1985;1:379-84.

18 Johnson RJ, Zhu XP, Isherwood I, et al. Computed tomography: qualitative and quantitative recognition of liver disease in haemophilia. J Comput Assist Tomogr 1983;7:1000-6.

19 Foley WD, Varma RR, Lawson TL, Berland LL, Smith DF, Thorsen K. Dynamic computed tomography and duplex ultrosonography: J Comput Assist Tomogr 1983;7:77-82.

20 Webb LJ, Berger LA, Sherlock S. Grey scale ultrasound of portal vein. Lancet 1977;ii:675-7.

21 Weinreb J, Kumari S, Phillips G, Pochaczevsky R. Portal vein measurements by real-time sonography. AJR 1982;139:497-9.

Requests for reprints to: Dr Christine A Lee, Haemophilia Centre, Royal Free Hospital, Pond Street, London NW3 2QG, England. 